\title{
The application of ultrafiltration for separation of glycerol solution fermented by bacteria
}

\author{
Wirginia Tomczak, Marek Gryta \\ West Pomeranian University of Technology, Szczecin, Institute of Chemical Technology and Environment Engineering, \\ ul. Pułaskiego 10, 70-322 Szczecin, Poland
}

\begin{abstract}
A biotechnological synthesis generated a fermentation broth containing the dissociated forms of organic compounds and residual mineral salts. An effective method of selective removal of the ionic species and organic compounds from solutions comprises nanofiltration and reverse osmosis. Ultrafiltration (UF) was used in this work as a pre-treatment method for the preparation of feed for these processes. The UF study was carried out with a real broth, which was obtained using Citrobacter freundii bacteria for the fermentation of glycerol solutions, resulting in the UF permeate with turbidity below 0.1 NTU. However, a significant decline of the permeate flux was observed during the UF process. The influence of the transmembrane pressure on the fouling intensity of used ceramic membranes was investigated. A periodical membrane cleaning was carried out by rinsing with water and a $1 \mathrm{wt} \%$ solution of sodium hydroxide. The applied cleaning procedures permitted to restore the initial permeate flux.
\end{abstract}

Keywords: ultrafiltration, fouling, ceramic membrane, glycerol fermentation.

\section{INTRODUCTION}

During the production of biodiesel, is generated a large amount of raw glycerol as a by-product comprising $10 \mathrm{wt} \%$ of fuel production ${ }^{1}$. The usage of crude glycerol as a substrate for biotechnological synthesis of different organic compounds (such as 1,3-propanediol) has been proposed in several works ${ }^{1-8}$. The fermentation process generates a broth containing the dissociated and non-dissociated forms of metabolites and residual mineral salts (nutrients). Various unit operations are required for the purification, concentration, and the separation of organic compounds from the fermentation broth ${ }^{\text {9-11. }}$. The methods used for the separation of 1,3-propanediol from fermentation broth based on the following stages: removal of biomass, removal of proteins, concentration of broth, and the separation of 1,3-propanediol by silica gel chromatography, were also presented ${ }^{12}$. With regard to a complex composition of the broth, the applied separation methods require a multi-stage operation, and the membrane processes constitute their important element. The nanofiltration (NF) and reverse osmosis (RO) has been successfully used for the separation of compounds present in the broth ${ }^{13}{ }^{14}$. Due to a high turbidity of the broth, resulting from the content of microorganisms, the separation of this broth cannot be directly performed with the use of spiral-wound membrane modules, therefore, the broth should be subjected to the pre-treatment. The mirco- and ultrafiltration processes can be used for this purpose $^{14,15}$.

Ultrafiltration (UF) is a low-pressure membrane technique (0.1-0.7 MPa) in which the separation of dissolved matter depends on their dimensions and the molecular weight. The UF process is widely used in many industrial applications. In the food industry, this process can be used to replace the conventional concentration, separation and purification methods ${ }^{16,17}$. Moreover, the UF process is also proposed for the removal of high-molecular organic compounds from natural waters, e.g. the substances causing their colour and the turbidity. Ultrafiltration is also an effective method for the separation of bioproducts and microorganisms from fermentation broths ${ }^{18}$.
Ultrafiltration and microfiltration were found to be the best pre-treatment methods for the removal from the feed the majority of the potential constituents responsible for the membrane fouling such as particles, colloids, bacteria and large molecular weight organic matters ${ }^{15-18}$. These clarification membrane processes also significantly reduce the silt density index to a level below $3^{15}$. Several works confirmed the effectiveness of application of the MF/UF integrated systems for seawater pre-treatment for water desalination by reverse osmosis. Although UF and MF processes are always protected by the use of a screen $(50-500 \mu \mathrm{m})$ and sometimes by upstream coagulation and other chemical processes, a flux decrease up to $50 \%$ (and larger) during a long-term treatment of natural waters was observed. The broths have several times larger fouling impact in comparison to the surface water and seawater, therefore, the effective membranes cleaning methods could be used in the case of UF integrated with bioreactor ${ }^{18,} 19$.

A cleaning operation is not completely efficient or may be aggressive for the membranes; hence, their performance undergo deterioration more or less quickly over the operational cycles. A frequent cleaning of the membranes may be costly (large energy and water consumption, excessive duration, effluent production) and could damage the membrane material, which results in reduced membrane lifetime and the selectivity ${ }^{20}$.

The ceramic membranes exhibit a high chemical and thermal resistance, which allows to perform the cleaning operation with acids and alkaline solutions at elevated temperature ${ }^{18,21}$. For these reasons, they found the application in the food industry, where the membranes have to be cleaned at least once a day in most cases for the recovery of the separation performances. Due to a high mechanical resistance of the ceramic membranes, during their exploitation can be used high operation pressures ${ }^{18,22}$. The chemical cleaning is usually carried out at a lower transmembrane pressure (TMP) than that used during the ultrafiltration operation. Under these conditions a compressible fouling layer is relaxed and an additional irreversible fouling originating from 
a high-applied TMP can be mitigated or eliminated. Several researchers reported that the cleaning time has a beneficial effect on the flux recovery ${ }^{23}$. When $\mathrm{NaOH}$ solutions were used for cleaning of the ceramic membranes, obtained data indicated that the removal of the main part of the fouling resistance took place within the first few minutes of cleaning (up to $12 \mathrm{~min}$ ) $^{24}$. Although the flow rate has an advantageous impact since the mechanical and chemical effects add up, its influence is lower than expected in UF. A rinsing efficiency of ceramic UF membrane fouled with proteins was found to be independent for flow rate between 2 and $6 \mathrm{~m} / \mathrm{s}^{25}$.

The major limitation in the effective application of membranes is a continuous decline of their yield caused by the accumulation of contaminants on the membrane surface or within the pores. A decrease of the membrane yield during the ultrafiltration process of macromolecules depends primarily on the interaction of separated molecules with the membrane, and is associated with the properties of material used for manufacture of UF membranes. Moreover, these interactions are affected by the composition of feeding solution and the process conditions (TMP, feed concentration, cross-flow velocity) ${ }^{15,19}$.

A number of presented works have a major drawback associated with the use of a model fermentation broths (containing e.g.: 1,3-propanediol, glycerol, glucose, and also in some cases a few other byproducts) for the evaluation of UF process performance. Therefore, the real broth was used as a feed for UF study. The ultrafiltration effectiveness in the broth separation was evaluated in this work by a comparison of the feed and permeate turbidity. The efficiency of alkaline chemical cleaning of the membranes was also determined.

\section{EXPERIMENTAL}

The real post-fermentation solutions were used as a feed for UF process with the ceramic membrane. The glycerol fermentation was carried out using Citrobacter freundii bacteria (isolated and characterized in Department of Biotechnology and Food Microbiology, Poznań University of Life Science, Poland), at temperature $300 \mathrm{~K}$. A prepared broth contained per liter: glycerol $20 \mathrm{~g}$, yeast extract $2 \mathrm{~g}$, meat extract $1.5 \mathrm{~g}$, peptone $\mathrm{K}$ $2.5 \mathrm{~g}, \mathrm{~K}_{2} \mathrm{HPO}_{4} \cdot 3 \mathrm{H}_{2} \mathrm{O} 3.4 \mathrm{~g}, \mathrm{KH}_{2} \mathrm{PO}_{4} \cdot 1.3 \mathrm{~g}, \mathrm{MgSO}_{4} \cdot 7 \mathrm{H}_{2} \mathrm{O}$ $0.4 \mathrm{~g},\left(\mathrm{NH}_{4}\right)_{2} \mathrm{SO}_{4} \cdot 2 \mathrm{~g}, \mathrm{CaCl}_{2} \cdot 2 \mathrm{H}_{2} \mathrm{O} 0.1 \mathrm{~g}$ and $\mathrm{CoCl}_{2} \cdot 6 \mathrm{H}_{2} \mathrm{O}$ $0.004 \mathrm{~g}$. After sterilization, the medium was inoculated with bacteria in a lag phase $(10 \% \mathrm{vv}$.) and incubated for 2 days. After this period, the fermented broth $(4 \mathrm{~L})$ was subjected to the separation by ultrafiltration.

A biomass concentration was estimated by measuring the weight of wet biomass present in $0.1 \mathrm{~L}$ of broth (6000 rpm, centrifuge MPW-350R, Med-Instruments, USA). Additionally, a series of broths dilution was prepared in a $\mathrm{NaCl}$ solution $(0.9 \%)$ and the obtained samples were placed on the MRS agar (BTL, Poland). The plates were incubated for $24 \mathrm{~h}$ at $303 \mathrm{~K}$ and the colony-forming units (CFU s/ml) were then counted. This experiment was verified three times. A statistical significance of the differences in daily growth rates was evaluated with one-way ANOVA test at $\mathrm{p} \leq 0.05$.

The ultrafiltration process was carried out in a pilot plant schematically shown in Fig. 1. The stainless-steel

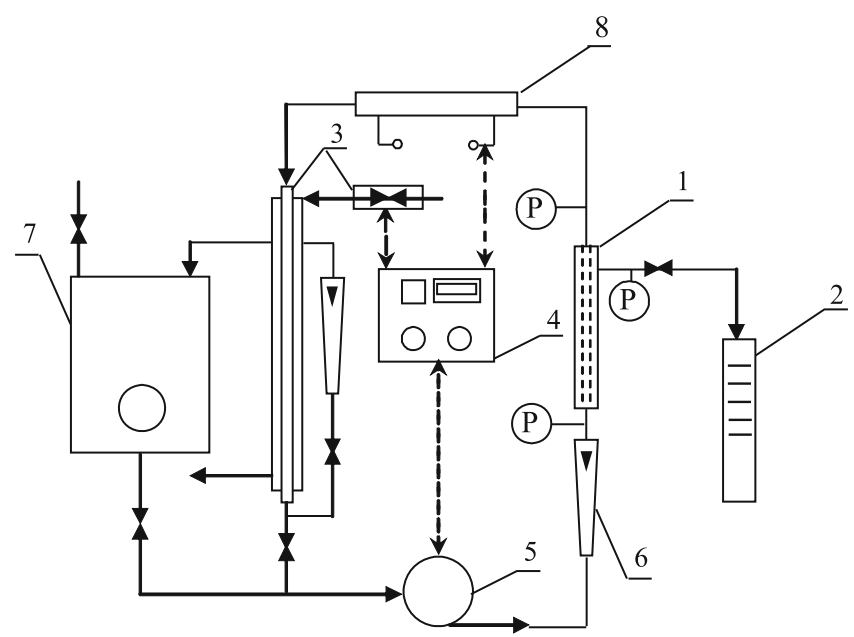

Figure 1. Experimental set-up for NF process. 1 - UF module, 2 - measuring cylinder, 3 - heat exchanger, 4 controler of temperature and flow rate, 5 - pump, 6 - rotameter, 7 - feed tank, 8 - heater, $\mathrm{P}$ - manometer

ASI 316 was used as a construction material. A single-channel (diameter $0.006 \mathrm{~m}$ ) UF ceramic membrane ( $8 \mathrm{kD}$ and the membrane area equal to $3.8 \cdot 10^{-3} \mathrm{~m}^{2}$ ) manufactured by TAMI (France) was used. The process was carried out at a temperature of $308 \mathrm{~K}$, and under TMP pressure in the range of $0.1-0.25 \mathrm{MPa}$ for $10-12 \mathrm{~h} /$ per day. The process temperature was controlled $( \pm 1 \mathrm{~K})$ and stabilized by a cooling/heating system (Fig. 1). When the temperature of the circulating liquid exceeded the set value, the cooling system was started and the temperature decreased. The volume of feed tank was $4 \mathrm{~L}$. The experiments were carried out using the feed flows in the range of $350-750 \mathrm{~L} / \mathrm{h}$, what corresponds to the flow velocity tangential to the membrane surface of 3.64-6.8 $\mathrm{m} / \mathrm{s}$, respectively. The rotameters were used for the measurements of flow rates. The actual values of maximal permeate flux were determined using the distilled water as a reference solution. After completing the studies of UF process, the pilot plant was subjected to the chemical cleaning. The cleaning procedure was as follows: rinsing the installation with distilled water $(10 \mathrm{~min})$, washing with a $1 \mathrm{wt} \%$ solution of sodium hydroxide for $5 \mathrm{~min}$, followed by rinsing with water for $5 \mathrm{~min}$.

The determination of separated solution compositions was performed using a high-performance liquid chromatograph HPLC UlitiMate 3000 (Dionex, USA) with refractometer detector RI-101 (Shodex) and column HyperREZ XP H (Thermo Scientific, USA), through which a $\mathrm{H}_{2} \mathrm{SO}_{4}$ solution $(0.005 \mathrm{M})$ was flowing $(0.6 \mathrm{ml} / \mathrm{min})$.

The hydraulic resistance appearing during the filtration can quantify the membrane fouling, and cleaning can be specified by the removal of this resistance. The resistance is due to the formation of a cake or gel layer on the membrane surface. The Darcy's law can by used for the description of the permeate flux through the cake layer and the membrane:

$J=\frac{\Delta P}{\mu\left(R_{m}+R_{F}\right)}$

wh ere $\Delta P$ is the transmembrane pressure (driving force), $\mu$ is viscosity of the fluid and $R_{m}$ and $R_{F}$ is the membrane and the fouling layer resistances, respectively. The feed viscosity was $0.94 \mathrm{cP}$, whereas that of the permeate was 
$0.86 \mathrm{cP}$ (BROOKFIELD viscometer DV-II+Pro with UL Adapter).

The membrane resistance $\left(R_{m}\right)$ can be estimated from the initial water flux, determined for clean membrane:

$J=\frac{\Delta P}{\mu R_{m}}$

\section{RESULTS AND DISCUSSION}

The permeate flux obtained during broths filtration was significantly lower than that for pure water, due to the deposition of foulants on the membrane surface ${ }^{25-28}$. Although the permeate flux was initially high, a rapid flux decline was observed during the first 100-200 min of UF process duration (Fig. 2). Finally, the flux reached a quazi-stabilization level for the next $600 \mathrm{~min}$. During the stabilization period the feed volume was reduced over two-fold, thus the flux decline observed at initial 200 min was not due to increased concentration of the feed. The initial concentration of the broths used in the studies amounted to $5-10 \mathrm{~g} / \mathrm{L}$ of wet biomass and was increasing to $25-34 \mathrm{~g} / \mathrm{L}$ in the obtained retentates. The concentration of Citrobacter freundii bacteria amounted to $9.16-11 \log \mathrm{CFU} / \mathrm{ml}$, and was slightly higher in the obtained retentates.

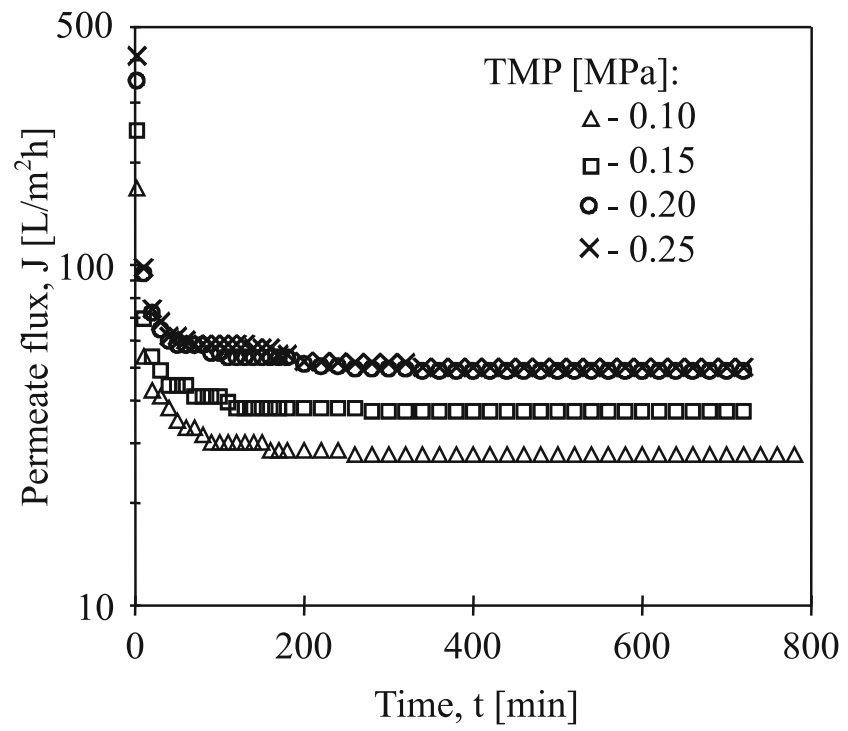

Figure 2. The influence of process time and the transmembrane pressure on the UF permeate flux. Feed flow rate $350 \mathrm{~L} / \mathrm{h}$

Most probably, the mechanism of cake layer formation has a dominant effect on the flux decline. As can be seen from Fig. 2, the values of used TMP have a significant influence on a level of flux stabilization. The permeate flux increased along with increasing TMP and as a result, the amount of biomass retained at the membrane surface was also increased, causing a decrease in the permeate flux along with feed flow rate decrease. Moreover, an increase in the transmembrane pressure results in a compression of the deposited layer on the membrane surface $^{21}$. As a result, the flux was no longer increased with the TMP (limiting flux). For the studied case (feed flow rate $350 \mathrm{~L} / \mathrm{h}$ ) this phenomenon was observed for TMP in the range of $0.2-0.25 \mathrm{MPa}$ (Fig. 2).

The fouling phenomenon in UF process is strongly affected by the diffusion and convection mechanisms ${ }^{16,18}$. An increase in the cross-flow velocity, which is associa- ted with an increase in the shear rate, also enhances the mass transfer of foulants in the fouling layer to the bulk solution, and it was confirmed by obtained results presented in Fig. 3. Although the turbulent conditions were obtained $(\operatorname{Re}=15000-30000)$ for all flow rates used $(350,500$ and $750 \mathrm{~L} / \mathrm{h})$, the permeate flux was decreasing according to a decrease in the feed flow rate. A high flow rate provides turbulence, which causes an increase in mass transfer, and can limit the fouling intensity. The foulants transport from the fouling layer to the bulk solution is also controlled by the transmembrane pressure. Due to TMP increase, the larger amounts of foulants were accumulated at the membrane surface, therefore, a greater influence of the flow rate (shear rate) was observed for the TMP equal to $0.25 \mathrm{MPa}$, than that for $0.2 \mathrm{MPa}$ (Fig. 3).

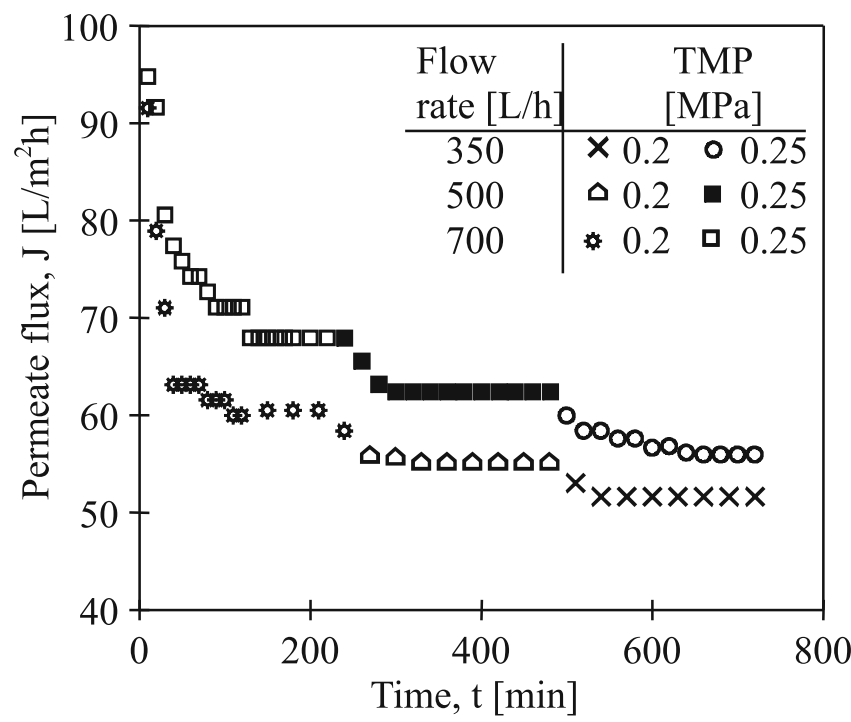

Figure 3. The influence of the transmembrane pressure and feed flow rate on the permeate flux during UF process of broths with Citrobacter freundii bacteria

The measurements of feed and permeate turbidity demonstrated a high degree of retention of suspended matter by used UF membrane (Fig. 4). Depending on the initial feed concentration and a value of TMP (permeate flux), the concentration of feed proceeded with different rate and the NTU value of the feed was changed in the range from 200 to 1300 NTU. The permeate with turbidity stabilized at a level of 0.1 NTU was obtained in each of these cases. During the first 20-50 minutes of UF process, the permeate turbidity was a tree-five times higher, and the stabilization time to achieve a value of 0.1 NTU decreased along with increasing TMP. This indicates that a fouling layer formed on the membrane surface improved the separation effectiveness. The filtrate obtained in the UF process with such a low turbidity can be successfully used for feeding of NF or RO spiral-wound modules?.

The feed and permeate composition was presented in Table 1. The UF membranes separated only the high molecular compounds. The molecular weight of used substrates and obtained fermentation products was below $300 \mathrm{~g} / \mathrm{mol}$, therefore, their concentrations in the feed and UF permeate was similar.

The membrane permeability decreases during the module exploitation; therefore, a periodical membrane 
Table 1. The changes of feed and permeate composition during the UF process

\begin{tabular}{|c|c|c|c|c|c|c|c|}
\hline Component & Broth & $\begin{array}{l}\text { Feed } \\
t=1 h\end{array}$ & $\begin{array}{c}\text { Permeate } \\
t=1 \mathrm{~h}\end{array}$ & $\begin{array}{l}\text { Feed } \\
t=3 h\end{array}$ & Permeate $\mathrm{t}=3 \mathrm{~h}$ & $\begin{array}{l}\text { Feed } \\
t=4 h\end{array}$ & $\begin{array}{c}\text { Permeate } \\
t=4 h\end{array}$ \\
\hline Citric acid & 2.55 & 2.55 & 2.49 & 2.66 & 2.54 & 2.51 & 2.56 \\
\hline Succinic acid & 0.37 & 0.38 & 0.37 & 0.36 & 0.36 & 0.36 & 0.36 \\
\hline Lactic acid & 1.40 & 1.44 & 1.46 & 1.40 & 1.39 & 1.40 & 1.42 \\
\hline Glicerol & 1.53 & 1.55 & 1.54 & 1.59 & 1.55 & 1.54 & 1.54 \\
\hline Acetic acid & 0.72 & 0.73 & 0.72 & 0.71 & 0.71 & 0.71 & 0.71 \\
\hline 1,3-PD & 3.45 & 3.65 & 3.66 & 3.66 & 3.62 & 3.63 & 3.63 \\
\hline
\end{tabular}

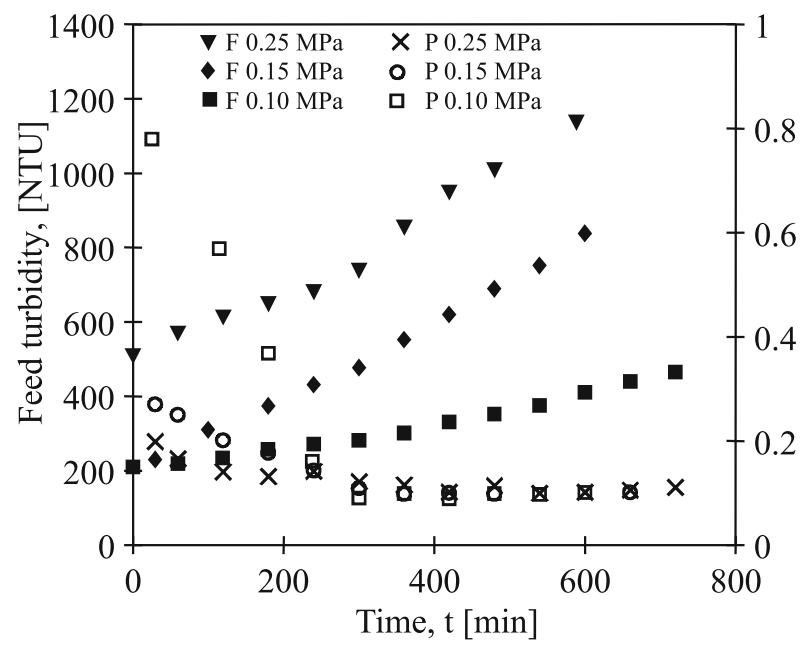

Figure 4. The influence of process time and the transmembrane pressure on the turbidity of feed and permeate. $\mathrm{F}-$ feed , P - permeate. Feed flow rate $350 \mathrm{~L} / \mathrm{h}$

cleaning should be applied. The fouling may be reversible or irreversible, the latter causing a permanent change in the membrane performance, thus the cleaning operation aims to remove all foulants either by physical, chemical or biochemical means ${ }^{16-20,23-28}$. With regard to chemical cleaning, there is no interest to increase the cleaning time beyond $20 \mathrm{~min}$, due to a plausible re-deposition (or re-fouling) process ${ }^{16}$. When the rinsing time of module with a $\mathrm{NaOH}$ solution was shortened to $5 \mathrm{~min}$, the preliminary studies demonstrated that similarly good results of cleaning were obtained as in the case of longer times (10 and $20 \mathrm{~min}$ ). For this reason, the time of chemical cleaning amounting $5 \mathrm{~min}$ was used in further studies. A module rinsing was performed after each cycle of the separation of fermentation broth, and the obtained results were presented in Fig. 5. Irrespective of the TMP applied and the obtained final concentration of the feed (Fig. 4), the initial yield of UF module was restored by the application of membrane cleaning with a 1 wt.\% $\mathrm{NaOH}$ solution for $5 \mathrm{~min}$. Moreover, the efficiencies higher than $100 \%$ after the membrane cleaning were obtained after $56 \mathrm{~h}$ of UF process. This may be a result of membrane damage associated with the formation of some large pores or tracks. The results of this work demonstrate that the end users should pay attention to a membrane specification.

Another explanation for cleaning efficiencies higher than $100 \%$ is based on the membrane hydrophilicity. A membrane characteristic, including its hydrophilicity, may be changed when the membrane is subjected to the action of various chemicals during the cleaning process. If the membrane is altered to operate in a more hydrophilic media, a higher flux can be expected.

The changes of membrane resistance during the different stages of UF study were presented in Fig. 6. The

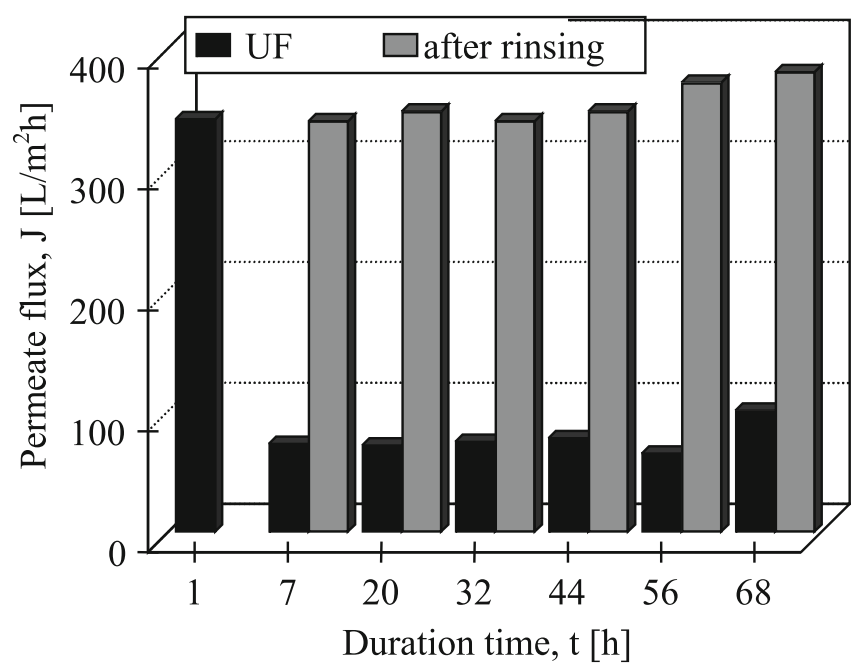

Figure 5. A comparison of the permeate flux (water as a feed) after UF process of broths and after module rinsing with 1 wt. $\% \mathrm{NaOH}$ solution. TMP $=0.2 \mathrm{MPa}$ and feed flow rate $350 \mathrm{~L} / \mathrm{h}$. The initial flux $(1 \mathrm{~h})$ was determined for clean membrane

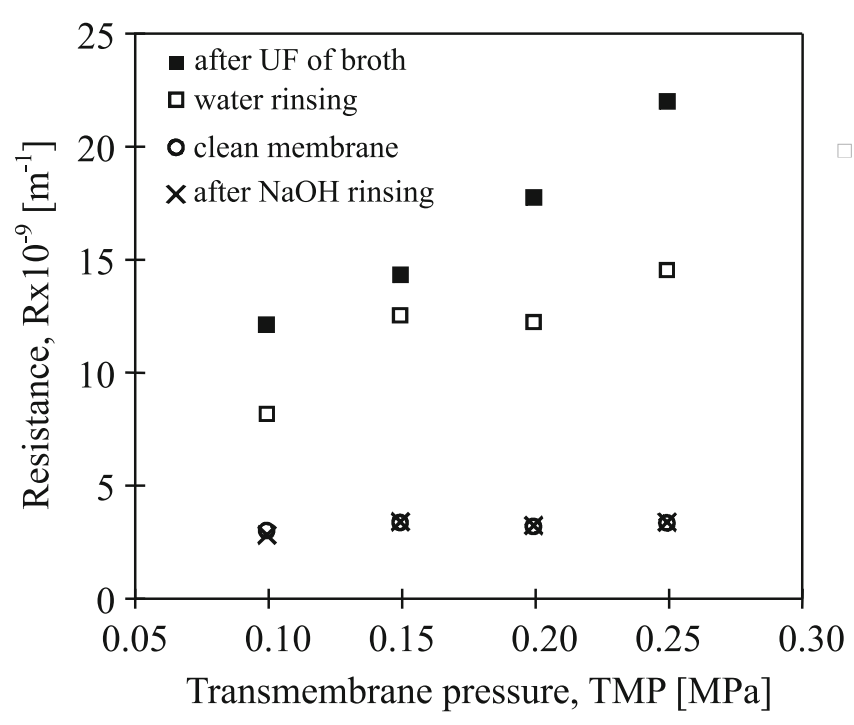

Figure 6. The effect of the transmembrane pressure on a membrane hydraulic resistance at different stages of UF experiment

resistance of clean membrane $\left(R_{m}\right)$ we can consider as equal to the average value of the initial membrane resistance calculated from (Eq. 2) for different TMP values. According to this calculation, the $R_{m}$ values is equal to $2.62 \times 10^{9} \pm 0.12 \times 10^{9} \mathrm{~m}^{-1}$. A significantly higher resistance, calculated for the stabilized flux from (Eq. 1) was obtained when the fouling layer was formed. In this case, the value of $\left(R_{m}+R_{F}\right)$ was dependent on the used TMP values and increased from $1.15 \times 10^{10}$ to $2.14 \times 10^{10} \mathrm{~m}^{-1}$ (Fig. 6). Further studies of the broth separation were carried out by the initial water rinse in order to remove a loosely bound fouling material from the membrane 
surface. The operating conditions were as follows: flow rate $3.4 \mathrm{~m} / \mathrm{s}(R e \approx 15000), \mathrm{TMP}=0$ bar, $298 \mathrm{~K}$ and process time of $10 \mathrm{~min}$. The water flux, measured after the first water rinse for TMP $=0.18 \mathrm{MPa}$, allowed to calculate the total irreversible fouling resistance. The calculated values were in the range of $7.54 \times 10^{9}$ to $1.39 \times 10^{10} \mathrm{~m}^{-1}$. Thus, it can be concluded that more than $65 \%$ of the mass transport resistance is associate with irreversible fouling. The larger values of resistance were obtained when the higher values of TMP were used for the broth separation. Probably, the increase in the TMP caused a compression of the deposited layer on the membrane surface. However, independently on the operation conditions of broth separation and the feed concentration, the application of the chemical cleaning $(\mathrm{NaOH})$ for 5 min restored the membrane resistance closed to that determined for the clean membrane (Fig. 6). The effectiveness of $\mathrm{NaOH}$ solutions applied for cleaning of the membranes which had been used for the separation of post-fermentation solutions was also demonstrated in other works ${ }^{16,18-25,27,28}$.

\section{CONCLUSIONS}

The application of UF process with ceramic membranes having the molecular weight cut-off equal to $8 \mathrm{kDa}$ for the separation of fermentation broths, allowed to obtain a filtrate with the turbidity at a level of 0.1 NTU. This value was practically independent both on the feed turbidity and concentration of the feed. Therefore, the ultrafiltration can be considered as a suitable pre-treatment method for the preparation of feed for nanofiltration and reverse osmosis, used for the separation of post-fermented solutions.

Due to the membrane fouling, the permeate flux decreased several times during 50-100 min of process and was stabilized at a level of $30-50 \mathrm{~L} / \mathrm{m}^{2} \mathrm{~h}$ depending on a value of applied TMP $(0.1-0.25 \mathrm{MPa})$.

A rinsing of module with water permitted to remove the deposits formed on the membrane surface only in a small degree. More than $65 \%$ of the resistance of fouled membranes was associated with the presence of irreversible foulants. The application of chemical cleaning (1 wt. \% NaOH) for 5 minutes restored the membrane hydraulic resistance close to that determined for clean membrane.

\section{ACKNOWLEDGMENT}

The study was conducted within the framework of the project: Biotechnological conversion of glycerol to polyols and dicarboxylic acids; (No 01.01.02-00-074/09) co-funded by The European Union from The European Regional Development Funds within the framework of the Innovative Economy Operational Programme 2007-2013.

\section{LITERATURE CITED}

1. Gungormusler, M., Gonen, C. \& Azbar, N. (2011). Continuous production of 1,3-propanediol using raw glycerol with immobilized Clostridium beijerinckii NRRL B-593 in comparison to suspended culture, Bioprocess Biosyst. Eng. 34, 727-733. DOI: 10.1007/s00449-011-0522-2.

2. Liu, B., Christiansen, K., Parnas, R., Xu, Z. \& Li, B. (2013). Optimizing the production of hydrogen and 1,3-propanediol in anaerobic fermentation of biodiesel glycerol, Int. J. Hydrogen Energy, 383, 196-205. DOI: 10.1016/j.ijhydene.2012.12.135.

3. Leja, K., Czaczyk, K. \& Myszka, K. (2011). The use of microorganisms in 1,3-Propanediol production, Afr. J. Microbiol. Res., 5 (26), 4652-4658. DOI: 10.5897/AJMR11.847.

4. Raynaud, C., Sarcabal, P., Meynial-Salles, I., Croux, Ch. \& Soucaille, P. (1993). Molecular characterization of the 1,3-propanediol (1,3-PD) operon of Clostridium butyricum, Appl. Microbiol. Biotechnol., 38, 453-457. DOI: 10.1073 pnas.0734105100.

5. Barbirato, F., Himmi, El H., Conte, T. \& Bories, A. (1998). 1,3-propanediol production by fermentation: An interesting way to valorize glycerin from the ester and ethanol industries, Ind. Crops Prod., 7, 281-289. DOI: 10.1016/S0926-6690(97)00059-9.

6. Metsoviti, M., Zeng, An.P., Koutinas, A.A. \& Papanikolaou, S. (2013). Enhanced 1,3-propanediol production by a newly isolated Citrobacter freundii strain cultivated on biodiesel-derived waste glycerol through sterile and non-sterile bioprocesses, J. Biotechnol., 163, 408-418. DOI: 10.1016/j.jbiotec.2012.11.018.

7. Anand, P. \& Saxena, R.K. (2012). A comparative study of solvent-assisted pretreatment of biodiesel derived crude glycerol of growth and 1,3-propanediol production from Citrobacter freundii, New Biotechol., 29, 199-205. DOI: 10.1016/j. nbt.2011.05.010.

8. Boenigk, R., Bowien, S. \& Gottschalk, G. (1993). Fermentation of glycerol to 1,3-propanediol in continuous cultures of Citrobacter freundii, Appl. Microbiol. Biotechnol., 38, 453-457. DOI: 10.1007/BF00242936.

9. Xiu, Z.L. \& Zeng, A.P. (2008). Present state and perspective of downstream processing of biologically produced 1,3-propanediol and 2,3-butanediol. Appl. Microbiol. Biotechnol., 78, 917-926. DOI: 10.1007/s00253-008-1387-4.

10. Li, Z., Jiang, B., Hang, D. \& Xiu, Z. ( 2009). Aqueous two-phase extraction of 1,3-propanediol from glycerol-based fermentation broths, Sep. Purif. Technol., 66, 472-478. DOI: 10.1016/j.seppur.2009.02.009.

11. Wu, R.C., Ren, H.J. Xu, Y.Z. \& Liu, D.H. (2010). The final recover of salt from 1,3-propanadiol fermentation broth. Sep. Purif. Technol, 73, 122-125. DOI: 10.1016/j.seppur.2010.03.013.

12. Annand, P., Saxena, R.K. \& Marwah, R.G. (2011). A novel downstream process for 1,3-propanediol from glycerol-based fermentation, Appl. Microbiol. Biotechnol., 90, 1267-1276. DOI: 10.1007/s00253-011-3161-2.

13. Vellenga, E. \& Trägårdh, G. (1998). Nanofiltration of combined salt and sugar solutions: coupling between retentions. Desalination, 120, 211-220. DOI: 10.1016/s00119164(98)00219-7.

14. Schäfer, A.I., Fane, A.G. \& Waite, T.D. (Eds.). (2005). Nanofiltration: Principles and applications. Oxford, UK: Elsevier Advanced Technology.

15. Bonnélye, V., Guey, L. \& Del Castillo, J. (2008). UF/ MF as RO pre-treatment: the real benefit, Desalination, 222, 59-65. DOI: 10.1016/j.desal.2007.01.129.

16. Blanpain-Avet, P., Migdal, J.F. \& Bénézech, T. (2009). Chemical cleaning of a tubular ceramic microfiltration membrane fouled with a whey protein concentrate suspension-Characterization of hydraulic and chemical cleanliness, J. Membr. Sci., 337, 153-174. DOI: 10.1016/j.memsci.2009.03.033.

17. Blanpain-Avet, P., Migdal, J.F. \& Bénézech, T. (2004). The effect of multiple fouling and cleaning cycles on a tubular ceramic microfiltration membrane fouled with $\mathrm{z}$ whey protein concentrate, Food Bioproducts Process., 82 (C3), 231-234. DOI: $10.1205 /$ fbio.82.3.231.44182.

18. Ogunbiyi, O.O., Miles, N.J. \& Hilal, N. (2008). The effects of performance and cleaning cycles of new tubular ceramic microfiltration membrane fouled with a model yeast suspension, Desalination, 220, 273-289. DOI: 10.1016/j.desal.2007.01.034.

19. Juang, R.S., Chen, H.L. \& Chen, Y.S. (2008). Resistance-in-series analysis in cross-flow ultrafiltration of fermentation broths of Bacillus subtilis culture, J. Membr. Sci., 323, 193-200. DOI: 10.1016/j.memsci.2008.06.032. 
20. Markardij, A., Chen, X.D. \& Farid, M.M. (1999). Microfiltration and ultrafiltration of milk: some aspects of fouling and cleaning, Food Bioproducts Process., 77, 107-113. DOI: $10.1205 / 096030899532394$.

21. Karasu, K., Glennon, N., Lawrence, N.D., Stevens, G.W., O'Connor, J.O., Barber, A.R., Yoshikawa, S. \& Kentish, S.E. (2010). A comparison between ceramic and polymeric membrane systems for casein concentrate manufacture, Int. J. Dairy Technol., 63 (2), 284-289. DOI: 10.1111/j.1471-0307.2010.00582.x.

22. Hwang, K.J., Wang, T.T., Iritani, E. \& Katagiri, N. (2010). Effect of gel particle softness on the performance of cross-flow microfiltration, J. Membr. Sci., 35, 130-137. DOI: 10.1016/j. memsci.2010.08.043.

23. Kazemimoghadam, M. \& Mohammadi, T. (2007). Chemical cleaning of ultrafiltration membranes in the milk industry, Desalination, 204, 213-218. DOI: 10.1016/j.desal.2006.04.030.

24. Blanpain-Avet, P., Migdal, J.F. \& Bénézech, T. (2004). The effect of multiple fouling and cleaning cycles on a tubular ceramic microfiltration membrane fouled with a whey protein concentrate. Membrane performance and cleaning efficiency, Food Bioproducts Process, 82 (C3), 231-243. DOI: 10.1205/ fbio.82.3.231.44182.

25. Cabero, M.L., Riera, F.A. \& Alvarez, R. (1999). Rinsing of ultrafiltration ceramic membranes fouled with whey proteins: effects on cleaning procedures, J. Membr. Sci. 154, 239-250. DOI: 10.1016/S0376-7388(98)00294-4.

26. Bachin, P., Aimar, P. \& Field, R.W. (2006). Critical and sustainable fluxes: Theory, experiments and applications, J. Membr. Sci., 281, 42-69. DOI: 10.1016/j.memsci.2006.04.014.

27. Nigam, M.O., Bansal, B. \& Chen, X.D. (2008). Fouling and cleaning of whey protein concentrate fouled ultrafiltration membranes, Desalination, 218, 313-322. DOI: 10.1016/j. desal.2007.02.027.

28. Madaeni, S.S. \& Mansourpanah, Y. (2004). Chemical cleaning of reverse osmosis membranes fouled by whey, Desalination, 161, 13-24. DOI: 10.1016/S0011-9164(04)90036-7. 